\title{
Improvement of the Ecological Protection Compensation Policy for Adjustment of Planting Structure in an Area of Groundwater Overexploitation: A Tripartite Evolutionary Game Study
}

\author{
Yuan Xiu, Ni Wang*, Jiancang Xie, Xinyue Ke \\ State Key Laboratory of Eco-hydraulics in Northwest Arid Region, Xi' an University of Technology, \\ Xi'an 710048, China
}

Received: 9 April 2021

Accepted: 10 September 2021

\begin{abstract}
The Beijing-Tianjin-Hebei region of China experiences overexploitation of groundwater (GW), mainly through agricultural water use. Planting structure adjustment (PSA) has proved to be effective in controlling GW use, although this inevitably affects the stakeholders. An ecological protection compensation (EPC) policy has been implemented simultaneously with PSA to meet the compensation needs of those who have lost profits. However, problems in policy design and implementation resulted in insufficient sustainability of the EPC. This study aimed to resolve these problems fundamentally by improving the current policy, based on the analysis of the interactions among the central government, the local government, and the farmers. Firstly, a mechanism for implemented economic penalties for violations was introduced. Secondly, the long-term interests and respective characteristics of all parties were taken into consideration. Finally, a tripartite evolutionary game model was established. Analysis based on evolutionary game theory allowed calculation of the constraints of the parameters in the model, which can drive the model to evolve in the expected direction. Under these constraints, the numerical simulations showed that: 1) information asymmetry should be minimized as much as possible during policy implementation; 2) reducing costs can accelerate self-convergence, but will not affect other participants; 3) the implementation of economic penalties can promote the evolution of the supervised party to evolutionary stability strategy; 4) improving the level of effort by farmers in implementing the policy is key to accelerating the evolution of the entire system.
\end{abstract}

Keywords: groundwater overexploitation, planting structure adjustment, ecological protection compensation, tripartite evolutionary game, penalties

e-mail: wangni@xaut.edu.cn 


\section{Introduction}

Both the economy and society have experienced unprecedented development on a global scale over the past few decades. However, this has come with the cost of insufficient resources and environmental and ecological challenges, which have aroused widespread concern among governments, scholars, and the public $[1,2]$. In particular, many developing countries have overexploited natural resources and sacrificed the environment to achieve national industrialization and modernization $[3,4]$. Groundwater $(\mathrm{GW})$ is an important water resource which can provide a stable water supply for agriculture, households, and industrial use in areas in which surface water resources are relatively scarce [5]. Irrigation accounts for about $70 \%$ of GW abstraction annually and $40 \%$ of global total irrigation [6]. GW is facing a crisis of overexploitation and pollution due to population growth, expansion of industry and agriculture, and poor management [7-11]. Studies have shown that GW levels have generally declined globally, particularly in the Mid-Atlantic region of the United States, California's Central Valley, northern India, the Middle East, and the North China Plain (NCP) [12-17]. At present, the GW funnel with the largest area and experiencing the fastest decline globally is in the NCP [18]. Long-term GW overexploitation has resulted in geological disasters and environmental problems, such as ground fissures, ground subsidence, GW funnel, GW pollution, and seawater intrusion [19-24]. China, similar to most countries, has been formulating more effective strategies to manage $\mathrm{GW}$ so as to achieve sustainable development [25].

The water balance principle indicates two possible methods for controlling GW overexploitation: (1) increasing GW recharge by water diversion projects; (2) reducing GW exploitation by increasing water conservation efforts [26]. The latter approach can be regarded as key to achieving sustainable GW use. The China State Council issued the "Action Programme for Comprehensive Treatment of GW Overexploitation in NCP" in 2019. This program has adopted the BeijingTianjin-Hebei (BTH) region in the northern part of the $\mathrm{NCP}$ as a key area for the comprehensive treatment of GW overexploitation. In Fig. 1, the distribution of GW overexploitation areas in BTH was shown. The BTH region forms a political, cultural, and scientific and technological hub in China. Therefore, this region is densely populated and contains developed industries. Meanwhile, this region is also important for national food production. The data provided by the Water Resources Bulletin of Beijing Municipality, Tianjin Municipality, and Hebei Province from 2004 to 2013 indicate that $72.8 \%$ of the total water consumed originated from $\mathrm{GW}$, with agricultural water consumption accounted for $62.8 \%$ of the total regional water consumption [27-29]. Thus, GW abstraction by agricultural sector is the main driver of GW overexploitation in the BTH region.

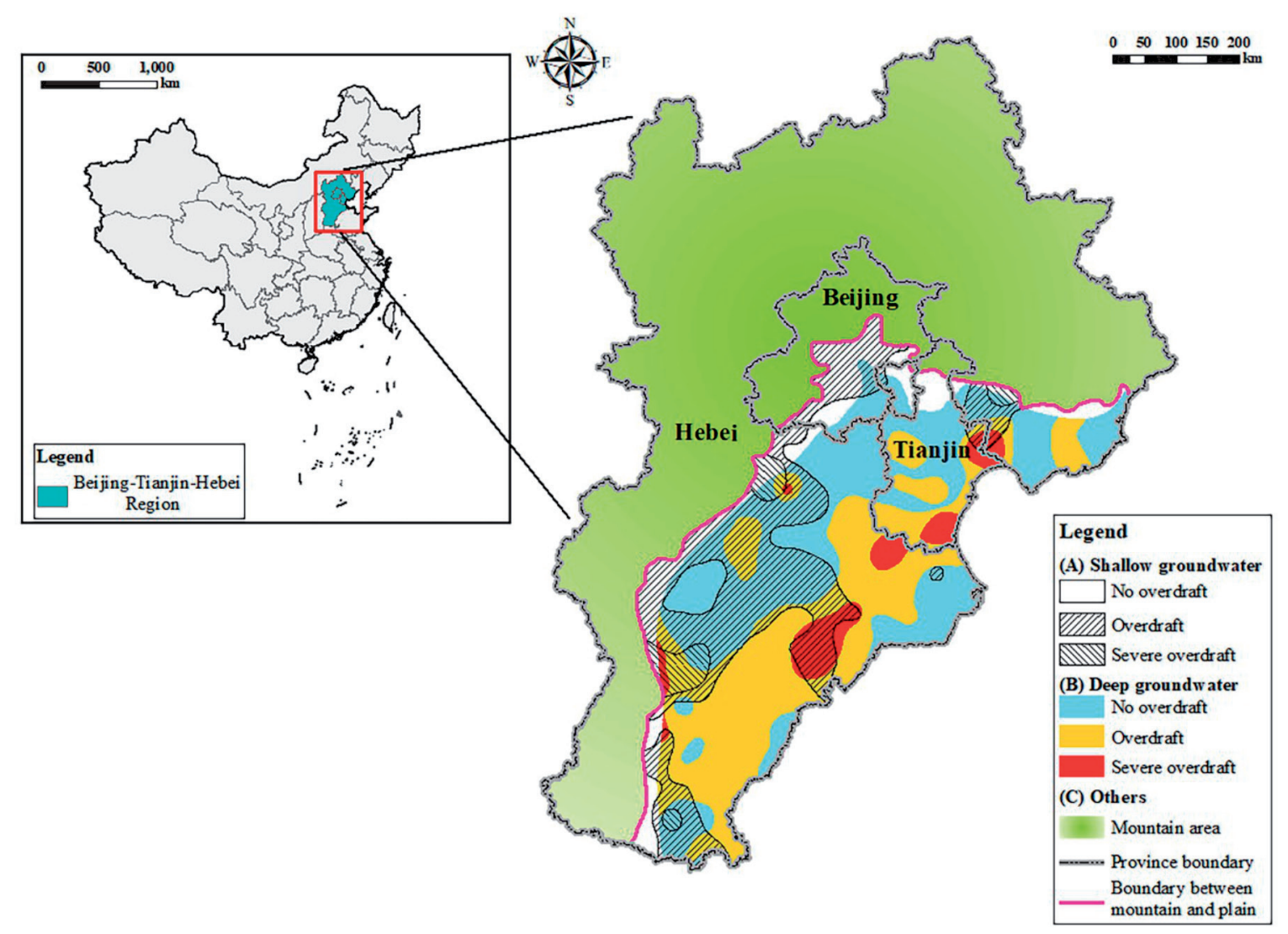

Fig. 1. The distribution of GW overexploitation areas in BTH. 
Planting structure adjustment (PSA) is the most effective approach to solve overexploitation of GW by agriculture. A winter wheat-summer maize rotation cropping system has remained the main planting pattern in North China for many decades [30, 31]. The central government $(\mathrm{CG})$ of China launched a pilot PSA project in the BTH region in 2014. Under this project, the cultivation of winter wheat in well irrigation district was prohibited. In addition, the cultivation of rain-fed crops was encouraged by introducing the cultivation of oil crops and drought-resistant grains during the rainy season. This planting mode was officially termed the "one season of fallow and one season of rain farming [32]. Farmers who have participated in PSA to conserve GW resources have clearly suffered economic losses due to PSA. Therefore, in response to farmers' demands for compensation, the government has formulated the ecological protection compensation (EPC) policy to compensate the farmers. Subsequently, it has been proved to show that the EPC policy promotes the sustainability of GW protection policies [26, 33].

The EPC policy of China is similar to the payments for ecosystem services (PES), which mainly uses economic means to regulate the relationships between stakeholders [34]. The EPC was initiated in the 1980s and has since been applied to the protection of forests, wetlands, and the watershed water environment.

Most past studies on EPC have focused on the calculation method and rationality of compensation standards. Yang et al. [35] quantitatively assessed the total ecological compensation for counties within the BTH region based on ecological assets and countylevel economic development. Liu et al. [36] constructed a water conservation compensation standard model based on the cost and contribution to water quality and water quantity related benefits, which they applied to the "Paddy Land-to-Dry Land Program" in the BeijingHebei region of China. Chu et al. [37] investigated the willingness of local households to accept compensation and identified the acceptable standard relating to afforestation policies. Xie et al. [38] analyzed the factors influencing the willingness of farmers to fallow winter wheat as well as ecological compensation standards in Hebei.

However, the aforementioned studies were based on the assumption that all parties involved in the EPC policy are able to fully perform their duties. In reality, the fact that all parties aim to maximize their own interests introduces the possibility that some stakeholders may not fully implement the policy. Therefore, there is value in analyzing the game relationship between stakeholders.

Evolutionary game theory (EGT) is suitable for analyzing dynamic cooperative relationships in which stakeholders may change strategies based on the information they have access to. EGT is particularly useful for analysis of the mutual influence among multiple entities within the implementation of policies [39]. EGT has been successfully applied in China for the analysis of the effectiveness of EPC in protecting water resources and water environment. $\mathrm{Lu}$ and Webber [40] established a tripartite game model of upper, middle, and lower streams users through EGT and simulated the evolutionary behavior of the game players within water quality contestations in the river basin. They then explored the mechanism and process controlling changes in water quality contestations in the river basin. Gao et al. [41] used EGT to explore the effectiveness of EPC for the East Route of the South-to-North Water Transfer Project. In particular, they analyzed the interactions among the upstream government, the downstream government, and the central government, as well as the various factors affecting the behavior of governments at all levels. Sheng et al. [42] studied the strategies of upstream users, downstream users, and the State Council Office in the East Route of the Southto-North Water Transfer Project through a tripartite evolutionary game model to explore an incentivecompatible system of payments for watershed services. The study highlighted the role of supervision and fines. However, these studies mainly focused on the EPC of surface water within the basin. Regrettably, there have been almost no studies on the process of EPC policy for GW protection.

Along with the implementation of EPC for PSA in the BTH region, there have been some challenges hindering the effectiveness of EPC. The local government (LG) is not capable of fully and effectively supervising farmers and neither can they provide technical guidance for farmers to switch to other crops. In order to obtain more economic benefits, farmers replanted on land that was designated to remain fallow in winter. The solution to these challenges is to improve the PSA policy itself with the goal of sustainability.

Tripartite evolutionary game is a type of evolutionary game. The three actors continue to improve their behaviors and simulate successful strategies in the evolution process, which in turn affects the evolution process of the system composed of the three. Therefore, the present study constructed a tripartite evolutionary game model to improve the EPC for PSA. Within the model, CG, LG, and farmers constituted the three stakeholders of the game. The model attempted to improve the sustainability of the policy by improving the payoff structure of stakeholders and considering the political losses, additional costs, and remedial cost resulting from incomplete implementation. Economic Penalties were added into the EPC for violations, which are missing in the current system. Finally, numerical simulation of the evolutionary stability strategy (ESS) provided references for the formulation of parameters in the EPC policy.

The remainder of this paper is organized as follows. Section 2 introduces the method in detail, including the basic problem, the basic assumptions, the construction of a tripartite evolutionary game model, and the replicated dynamic system as well as the constraint relationship that the relevant parameters should satisfy 
to achieve the expected goal of EPC policy. The results of model simulations are given in Section 3, along with the results of analyzing the impact of changes to parameters on the model. Section 4 presents the research conclusions.

\section{Material and Methods}

Stakeholders and Problem Description

\section{Stakeholders}

Since the environmental policy in China is a topdown policy, so is the EPC policy. The CG is primarily responsible for the design of policies. The CG adopted PSA with an EPC policy in BTH region in response to agricultural overexploitation of GW. This EPC policy involves three stakeholders: (1) the CG; (2) the LG and; (3) the farmers. Farmers, as the implementer of the policy, bear economic losses due to being prohibited from planting winter wheat and switching to rain-fed summer agriculture. The losses experienced by farmers are compensated by the joint funding of CG and LG. The LG is the agency of the CG and performs various roles, such as supervising farmers, providing farmers with technical guidance on planting, and bearing a certain percentage of the compensation payouts. The $\mathrm{CG}$, in addition to contributing to the compensation payouts to farmers and constructing the EPC policy, is responsible for providing policy and technical guidance to the LG. Fig. 2 shows that the stakeholders' relationship of EPC policy for PSA in the GW overexploitation area within the $\mathrm{BTH}$ region.

\section{Problem Description}

The EPC policy for PSA has already been in place for 6 years in the BTH. Therefore, this policy has greatly promoted the control of $\mathrm{GW}$ overexploitation. However, the expansion of the scope of the pilot program has exposed some challenges in the policy itself. The most prominent challenge is that the LG and farmers are unabThe effectiveness of policy often depends on the execution of the policy by the LG. The economic interests of the LG may conflict with the PSA policy. LG usually selects the strategy with the greatest expected return based on the characteristics of the LG. The responsibilities of the LG include not only supervising farmers in the process of PSA, but also bearing a portion of the compensation fees, which undoubtedly increase the cost to the LG in implementing the PSA policy. In addition, the state of the economy is important within the evaluation of LGs by the CG. Some studies have identified the main reason for the ineffectiveness of some China's environmental policies to be the focus of economic growth as the primary goal of the LG [43]. These reasons may explain why LG is motivated to not fully implement the PSA policy, which is a short-sighted strategy. However, the violations of LG have not been punished.

Farmers have experienced the most direct economic loss due to the PSA and the reduction in GW exploitation. Under the market economy system, farmers can only be motivated to participate in the PSA by obtaining a higher income by the adjustment of planting structure. That is to say, maximizing selfinterest is the goal of farmers. The interest of farmers in the PSA is closely related to opportunity cost,

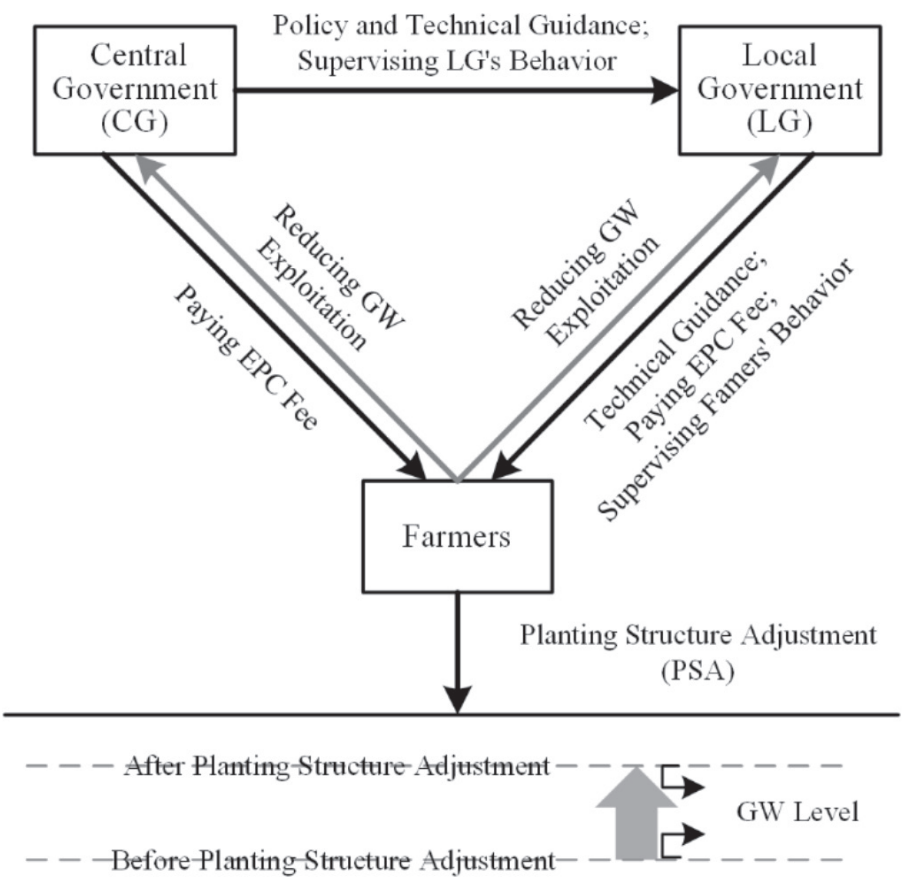

Fig. 2. The stakeholders' relationship of EPC policy for PSA in the GW overexploitation area in BTH. 
income after labor transfer, and the income structure of the family. Under the PSA, farmer income during the fallow period includes compensation funds and income from labor transfer. Farmers are motivated to replant on fallow land or to reclaim new farmland when income obtained through compensation and labor transfer is insufficient to make up for the loss. Unfortunately, the policy appears to be powerless for these violations except for verbal warnings.

An examination of the current EPC policy and existing challenges showed that the main reasons for insufficient policy sustainability are a lack of penalties for violations and an unreasonable income structure. Therefore, these were the goals of the current study.

\section{Construction of the Evolutionary Game Model}

\section{Basic Assumptions}

The current study aimed to improve the EPC policy to increase the sustainability of the policy. Various influencing factors were incorporated into the evolutionary model, including the levels of effort of the three stakeholders, the political loss by the government due to partial implementation of EPC, the remedial cost paid by the CG during the later period, and the penalty due to partial implementation. Therefore, this study made the following assumptions:

Assumption 1: According to the EGT, every stakeholder in the game is bounded rationality [44], and the adoption of strategies by stakeholders depends on the information they have access to. The CG, LG, and farmers can either choose to implement the policy fully or partially. Table 1 lists each stakeholder and their respective strategies. Obviously, the game is asymmetric.

Assumption 2: The ideal state of the EPC policy is that all three stakeholders adopt the complete implementation strategy.

Assumption 3: The $\mathrm{CG}$ adopts the maximization of social welfare as the starting point within the construction of EPC policy. The probability that the CG provides complete policy guidance and strict supervision to the $\mathrm{LG}$ is $x \in[0,1]$. Accordingly, the probability

Table 1. The strategies of stakeholders.

\begin{tabular}{|c|c|c|c|}
\hline Stakeholders & Symbol & Strategies & Code \\
\hline \multirow{2}{*}{$\begin{array}{c}\text { Central } \\
\text { Government }\end{array}$} & \multirow{2}{*}{$c g$} & $\begin{array}{c}\text { Complete } \\
\text { implementation }\end{array}$ & 1 \\
\hline & & Partial implementation & 2 \\
\hline \multirow{2}{*}{$\begin{array}{c}\text { Local } \\
\text { Government }\end{array}$} & \multirow{2}{*}{$\lg$} & $\begin{array}{c}\text { Complete } \\
\text { implementation }\end{array}$ & 1 \\
\hline & & Partial implementation & 2 \\
\hline \multirow{2}{*}{ Famers } & \multirow[t]{2}{*}{$f$} & $\begin{array}{c}\text { Complete } \\
\text { implementation }\end{array}$ & 1 \\
\hline & & Partial implementation & 2 \\
\hline
\end{tabular}

of partial implementation of the EPC is $1-x$. The effort level of the CG is $\lambda_{1} \in[0,1]$ when it chooses the strategy of partial implementation.

Under the situation of the CG choosing the strategy of complete implementation, the CG will pay the cost $C_{1}$, which is used for the supervision and the policy guidance of the LG. Since the LG falls beneath CG in hierarchical structure, the CG has the jurisdiction to punish the LG for violations, including an economic penalty $F_{1}$ and political accountability $P . C_{1}, F_{1}$, and $P$ are only related to the level of effort taken by the CG. At the same time, the CG bears some of the EPC fee $E$ for farmers in the proportion of $\theta \in[0,1]$.

Under a situation of $\mathrm{CG}$ choosing to partially implement the strategy, the behavior of the CG will result in political losses $B_{1}$ to itself, but also increase the cost to $L G$ in a proportion to $\left(1-\lambda_{1}\right)$.

Assumption 4: For LG, suppose that the probability of the LG conducting strict supervision and comprehensive technical guidance to farmers is $y \in[0,1]$; then $1-y$ is the probability that LG chooses the second strategy. The level of effort is $\lambda_{2} \in[0,1]$ when LG chooses the strategy of partial implementation.

Under the situation of the LG chooses the strategy of complete implementation, it will pay a cost $C_{2}$ and part of the EPC fee $(1-\theta) E$. The LG imposes an economic penalty of $F_{2}$ to farmers who replant fallow land or reclaim new farmland.

Under a situation of LG choosing partial implementation, it will bear political losses $B_{2}$ from farmers. Since LG is the agency of $C G$, the $C G$ will bear the political losses $\beta B_{2}$ from farmers. Under this strategy, the LG can obtain additional benefits $\left(1-\lambda_{2}\right)$ $N$ while saving costs. The cost of farmers will also increase at an increasing degree of $\left(1-\lambda_{2}\right)$ since they cannot obtain agronomic guidance.

Assumption 5: The strategy of the farmers will revolve around the maximization of benefits. The probability that the farmers will fully comply with the agreement to adjust the planting structure is $z \in[0,1]$, and the probability that farmers will violate the policy is $1-z$. $\lambda_{3} \in[0,1]$ represents the level of effort by farmers under partial implementation.

Farmers will receive an EPC fee of $E$ if they adjust planting structure according to the policy. During the fallow period, farmers can engage in non-agricultural work to obtain income $T$ generated by labor transfer. In addition, cost $C_{3}$ represents the loss resulting from fallowing of land and switching to other crops, which is the opportunity cost of participating in PSA policy.

$T$ and $C_{3}$ will be reduced under the situation of farmers choosing partial implementation. In this case, GW will remain overexploited. Therefore, CG will pay a remedy cost $G$ for this behavior representing subsequent remedial costs.

Assumption 6: The effect of PSA is to reduce the amount of GW extraction and restore the GW level. The ecological environment of the GW overexploitation area will thereby improve. This represents the goal of 
formulating EPC policy for PSA. Correspondingly, fallowing of agricultural land will reduce agricultural output, resulting in a negative impact on the economy.

The ecological benefit of $\mathrm{CG}$ was set as $V_{1}$ whereas the economic loss was set as $L_{1}$. The ecological benefit and the economic loss of the LG were set as $V_{2}$ and $L_{2}$, respectively.

Relevant notation and definitions are further described in Table 2. Fig. 3 shows the benefits and losses of every stakeholder under different strategies. The dark green parts and dark gray parts in Fig. 3 represent the expenditure and income that need to be added to the model after the EPC policy was improved respectively.

\section{Stakeholders'Payoffs}

As shown in Table 3, the present study established a tripartite evolutionary game model payoff matrix of eight strategy combinations among stakeholders. In the strategy combinations, $Q_{\mathrm{i}}$ represents the payoff of $\mathrm{CG}$, $R_{\mathrm{i}}$ represents the payoff of $\mathrm{LG}$, and $S_{\mathrm{i}}$ is the payoff of farmers, where $i=1,2, \ldots 8$.

When CG, LG, and farmers all choose the strategy of complete implementation.

The payoff of $C G$ is defined as:

$$
Q_{1}=V_{1}-L_{1}-C_{1}-\theta \times E
$$

The payoff of LG is defined as:

$$
R_{1}=V_{2}-L_{2}-C_{2}-(1-\theta) E
$$

The payoff of farmers is defined as:

$$
S_{1}=E+T-C_{3}
$$

When CG and farmers both choose the strategy of complete implementation and the LG chooses the strategy of partial implementation.

The payoff of CG is defined as:

$$
Q_{2}=V_{1}-L_{1}-C_{1}-\theta E-\beta B_{2}+F_{1}
$$

The payoff of LG is defined as:

$$
R_{2}=V_{2}-L_{2}-\lambda_{2} C_{2}-(1-\theta) E-F_{1}-P-B_{2}+\left(1-\lambda_{2}\right) N
$$

The payoff of farmers is defined as:

$$
S_{2}=E+T-C_{3}-\left(1-\lambda_{2}\right) C_{3}
$$

\begin{tabular}{|c|c|}
\hline Parameters & Descriptions \\
\hline$x$ & $\begin{array}{l}\text { CG's probability with complete } \\
\text { implementation strategy }\end{array}$ \\
\hline$y$ & $\begin{array}{l}\text { LG's probability with complete } \\
\text { implementation strategy }\end{array}$ \\
\hline$z$ & $\begin{array}{l}\text { Farmers' probability with complete } \\
\text { implementation strategy }\end{array}$ \\
\hline$V_{1}$ & $\begin{array}{l}\text { CG's ecological benefit due to farmers' full } \\
\text { implementation }\end{array}$ \\
\hline$V_{2}$ & $\begin{array}{l}\text { LG's ecological benefit due to farmers' full } \\
\text { implementation }\end{array}$ \\
\hline$L_{1}$ & $\begin{array}{l}\text { CG's economic loss due to farmers' full } \\
\text { implementation }\end{array}$ \\
\hline$L_{2}$ & $\begin{array}{l}\text { LG's economic loss due to farmers' full } \\
\text { implementation }\end{array}$ \\
\hline$C_{1}$ & $\begin{array}{c}\text { Cost of CG with complete implementation } \\
\text { strategy }\end{array}$ \\
\hline$C_{2}$ & $\begin{array}{c}\text { Cost of LG with complete implementation } \\
\text { strategy }\end{array}$ \\
\hline$C_{3}$ & $\begin{array}{c}\text { Cost of farmers with complete implementation } \\
\text { strategy }\end{array}$ \\
\hline$\lambda_{1}$ & CG's effort level \\
\hline$\lambda_{2}$ & LG's effort level \\
\hline$\lambda_{3}$ & Farmers' effort level \\
\hline E & Ecological protection compensation fee \\
\hline$\theta$ & The proportion of $E$ shared by CG \\
\hline$F_{1}$ & The economic penalty imposed by CG on LG \\
\hline$F_{2}$ & $\begin{array}{l}\text { The economic penalty imposed by CG on } \\
\text { farmers }\end{array}$ \\
\hline$B_{1}$ & $\begin{array}{l}\text { Political loss of CG with partial } \\
\text { implementation strategy }\end{array}$ \\
\hline$B_{2}$ & $\begin{array}{l}\text { Political loss of LG with partial } \\
\text { implementation strategy }\end{array}$ \\
\hline$\beta$ & The proportion of $E$ shared by CG \\
\hline$G$ & $\begin{array}{l}\text { CG's remedial cost caused by farmers' partial } \\
\text { implementation }\end{array}$ \\
\hline$N$ & $\begin{array}{l}\text { LG's additional benefit caused by partial } \\
\text { implementation of LG }\end{array}$ \\
\hline$P$ & $\begin{array}{l}\text { Political accountability of LG from CG, when } \\
\text { LG adopted partial implementation strategy }\end{array}$ \\
\hline$T$ & Farmers' income from labor transfer \\
\hline
\end{tabular}

When CG chooses the strategy of partial implementation, LG and farmers both choose the strategy of complete implementation.
Table 2. Parameters symbol descriptions.

The payoff of CG is defined as:

$$
Q_{3}=V_{1}-L_{1}-\lambda_{1} C_{1}-\theta E-\left(1-\lambda_{1}\right) B_{1}
$$

The payoff of LG is defined as:

$$
R_{3}=V_{2}-L_{2}-C_{2}-(1-\theta) E-\left(1-\lambda_{1}\right) C_{2}
$$




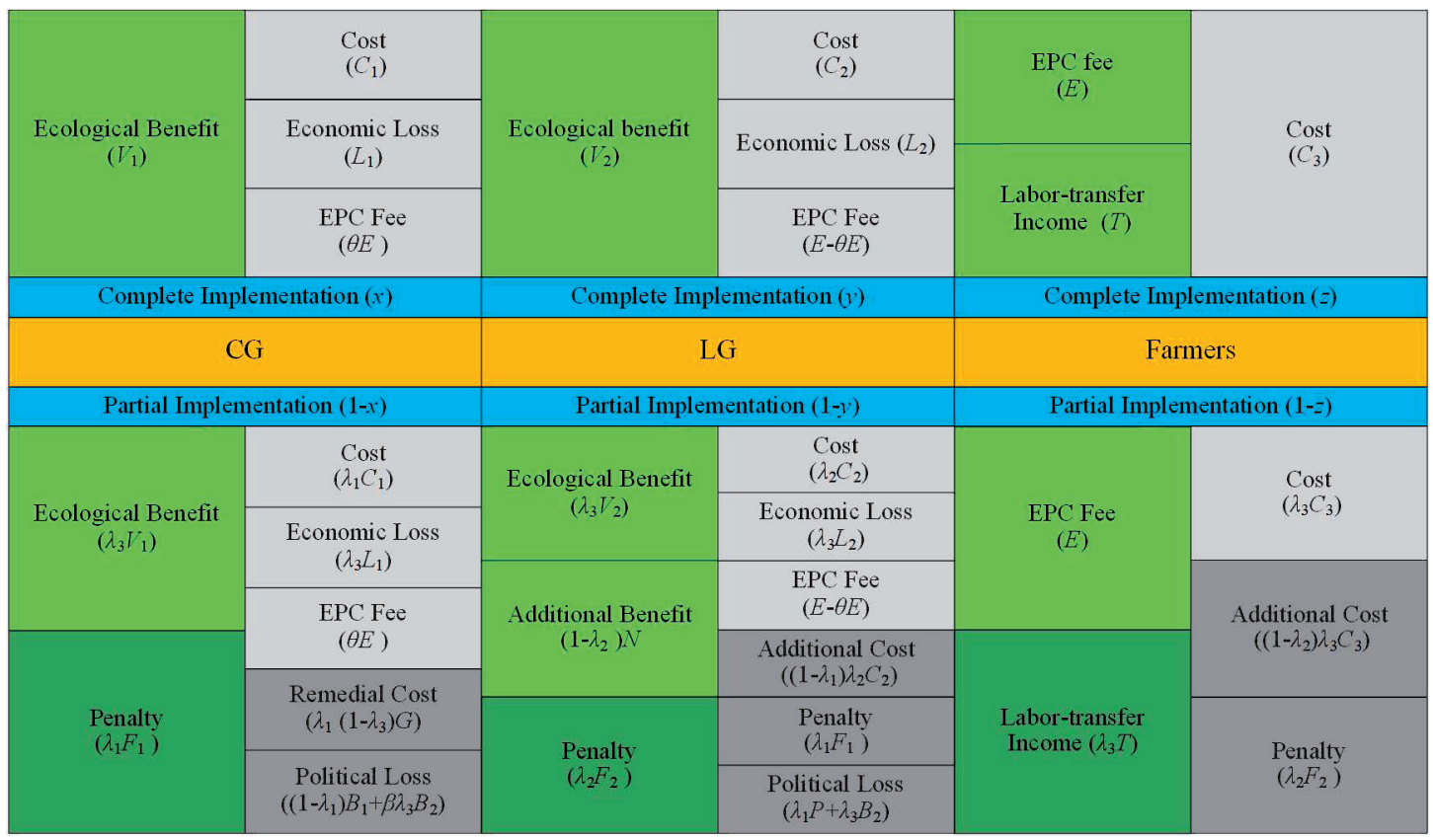

Fig. 3. The structure of stakeholders' interest in different strategies.

The payoff of farmers is defined as:

$$
S_{3}=E+T-C_{3}
$$

When CG and LG both choose the strategy of partial implementation, farmers choose the strategy of complete implementation.

The payoff of CG is defined as:

$$
Q_{4}=V_{1}-L_{1}-\lambda_{1} C_{1}-\theta E-\beta B_{2}-\left(1-\lambda_{1}\right) B_{1}+\lambda_{1} F_{1}
$$

The payoff of LG is defined as:

$$
\begin{gathered}
R_{4}=V_{2}-L_{2}-\lambda_{2} C_{2}-(1-\theta) E-\left(1-\lambda_{1}\right) \lambda_{2} C_{2} \\
-\lambda_{1} F_{1}-\lambda_{1} P-B_{2}+\left(1-\lambda_{2}\right) N
\end{gathered}
$$

The payoff of farmers is defined as:

$$
S_{4}=E+T-C_{3}-\left(1-\lambda_{2}\right) C_{3}
$$

When CG and LG both choose the strategy of complete implementation, farmers choose the strategy of partial implementation.
The payoff of CG is defined as:

$$
Q_{5}=\lambda_{3} V_{1}-\lambda_{3} L_{1}-C_{1}-\theta E-\left(1-\lambda_{3}\right) G
$$

The payoff of LG is defined as:

$$
R_{5}=\lambda_{3} V_{2}-\lambda_{3} L_{2}-C_{2}-(1-\theta) E+F_{2}
$$

The payoff of farmers is defined as:

$$
S_{5}=E+\lambda_{3} T-\lambda_{3} C_{3}-F_{2}
$$

When CG chooses the strategy of complete implementation, LG and farmers both choose the strategy of partial implementation.

The payoff of $\mathrm{CG}$ is defined as:

$$
Q_{6}=\lambda_{3} V_{1}-\lambda_{3} L_{1}-C_{1}-\theta E-\left(1-\lambda_{3}\right) G-\beta \lambda_{3} B_{2}+F_{1}
$$

The payoff of $\mathrm{LG}$ is defined as:

$$
\begin{gathered}
R_{6}=\lambda_{3} V_{2}-\lambda_{3} L_{2}-\lambda_{2} C_{2}-(1-\theta) E-F_{1}-P . \\
-\lambda_{3} B_{2}+\lambda_{2} F_{2}+\left(1-\lambda_{2}\right) N
\end{gathered}
$$

Table 3. The payoff matrix of the tripartite evolutionary game model.

\begin{tabular}{|c|c|c|c|c|}
\hline & \multicolumn{2}{|c|}{ CG strategy 1 } & \multicolumn{2}{c|}{ CG strategy 2 } \\
\hline & LG strategy 1 & LG strategy 2 & LG strategy 1 & LG strategy 2 \\
\hline Farmers strategy 1 & $\left(Q_{1}, R_{1}, S_{1}\right)$ & $\left(Q_{2}, R_{2}, S_{2}\right)$ & $\left(Q_{3}, R_{3}, S_{3}\right)$ & $\left(Q_{4}, R_{4}, S_{4}\right)$ \\
\hline Farmers Strategy 2 & $\left(Q_{5}, R_{5}, S_{5}\right)$ & $\left(Q_{6}, R_{6}, S_{6}\right)$ & $\left(Q_{7}, R_{7}, S_{7}\right)$ & $\left(Q_{8}, R_{8}, S_{8}\right)$ \\
\hline
\end{tabular}


The payoff of farmers is defined as:

$$
S_{6}=E+\lambda_{3} T-\lambda_{3} C_{3}-\lambda_{2} F_{2}-\left(1-\lambda_{2}\right) \lambda_{3} C_{3}
$$

When CG and farmers both choose the strategy of partial implementation, LG chooses the strategy of complete implementation.

The payoff of CG is defined as:

$Q_{7}=\lambda_{3} V_{1}-\lambda_{3} L_{1}-\lambda_{1} C_{1}-\theta E-\left(1-\lambda_{3}\right) \lambda_{1} G-\left(1-\lambda_{1}\right) B_{1}$

The payoff of $L G$ is defined as:

$$
R_{7}=\lambda_{3} V_{2}-\lambda_{3} L_{2}-C_{2}-(1-\theta) E-\left(1-\lambda_{1}\right) C_{2}+F_{2}
$$

The payoff of farmers is defined as:

$$
S_{7}=E+\lambda_{3} T-\lambda_{3} C_{3}-F_{2}
$$

When CG, LG, and farmers all choose the strategy of partial implementation.

The payoff of CG is defined as:

$$
\begin{gathered}
Q_{8}=\lambda_{3} V_{1}-\lambda_{3} L_{1}-\lambda_{1} C_{1}-\theta E-\left(1-\lambda_{3}\right) \lambda_{1} G \\
-\beta \lambda_{3} B_{2}-\left(1-\lambda_{1}\right) B_{1}+\lambda_{1} F_{1}
\end{gathered}
$$

The payoff of LG is defined as:

$$
\begin{aligned}
R_{8}= & \lambda_{3} V_{2}-\lambda_{3} L_{2}-\lambda_{2} C_{2}-(1-\theta) E_{1}-\lambda_{1} F_{1}-\lambda_{1} P \\
& -\left(1-\lambda_{1}\right) \lambda_{2} C_{2}-\lambda_{3} B_{2}+\left(1-\lambda_{2}\right) N+\lambda_{2} F_{2}
\end{aligned}
$$

The payoff of farmers is defined as:

$$
S_{8}=E+\lambda_{3} T-\lambda_{3} C_{3}-\lambda_{2} F_{2}-\left(1-\lambda_{2}\right) \lambda_{3} C_{3}
$$

\section{Replicated Dynamics of Stakeholders}

In deriving the utility functions based on the matrices shown in Table 3, $U_{c g 1}$ represents the expected payoff of the CG when it adopts the complete implementation strategy, $U_{c g 2}$ represents the expected payoff of the CG when it adopts the partial implementation strategy, and $U_{c g}$ represents the CG's expected utility that is the average payoff of the $\mathrm{CG}$, giving:

$$
U_{c g 1}=y z Q_{1}+y(1-z) Q_{5}+(1-y) z Q_{2}+(1-y)(1-z) Q_{6}
$$

$U_{c g 2}=y z Q_{3}+y(1-z) Q_{7}+(1-y) z Q_{4}+(1-y)(1-z) Q_{8}$

$$
U_{c g}=x U_{c g 1}+(1-x) U_{c g 2}
$$

Then, the dynamic replication equation of CG taking the strategy of complete implementation is:

$$
\begin{aligned}
F_{1}(x)= & \frac{d x}{d t}=x\left(U_{c g 1}-U_{c g}\right) \\
= & x(1-x)\left\{\left[\left(Q_{1}-Q_{3}\right)-\left(Q_{5}-Q_{7}\right)\right] y z+\left(Q_{5}-Q_{7}\right) y\right. \\
& \left.+\left[\left(Q_{2}-Q_{4}\right)-\left(Q_{6}-Q_{8}\right)\right](1-y) z+\left(Q_{6}-Q_{8}\right)(1-y)\right\}
\end{aligned}
$$

$U_{l g 1}$ represents the expected payoff of the $\mathrm{LG}$ when it adopts the complete implementation strategy, $U_{l g 2}$ represents the expected payoff of the LG when it adopts the partial implementation strategy, and $U_{l g}$ represents the average payoff of the LG, giving:

$$
U_{l g 1}=x z R_{1}+x(1-z) R_{5}+(1-x) z R_{3}+(1-x)(1-z) R_{7}
$$

$U_{\lg 2}=x z R_{2}+x(1-z) R_{6}+(1-x) z R_{4}+(1-x)(1-z) R_{8}$

$$
U_{l g}=y U_{l g 1}+(1-y) U_{l g 2}
$$

Then, the dynamic replication equation of the LG when adopting the strategy of complete implementation is as follows:

$$
\begin{aligned}
F_{2}(y)= & \frac{d y}{d t}=y\left(U_{l g 1}-U_{l g}\right) \\
= & y(1-y)\left\{\left[\left(R_{1}-R_{2}\right)-\left(R_{5}-R_{6}\right)\right] x z+\left(R_{5}-R_{7}\right) x\right. \\
& \left.+\left[\left(R_{3}-R_{4}\right)-\left(R_{7}-R_{8}\right)\right](1-x) z+\left(R_{7}-R_{8}\right)(1-x)\right\}
\end{aligned}
$$

$U_{f 1}$ is the expected payoff of farmers that adopt the complete implementation strategy and $U_{f 2}$ is the expected payoff of farmers that adopt the partial implementation strategy. Then, $U_{f}$ represents the average payoff of farmers. The three are as follows:

$$
U_{f 1}=x y S_{1}+x(1-y) S_{2}+(1-x) y S_{3}+(1-x)(1-y) S_{4}
$$

$U_{f 2}=x y S_{5}+x(1-y) S_{6}+(1-x) y S_{7}+(1-x)(1-y) S_{8}$

$$
U_{f}=z U_{f 1}+(1-z) U_{f 2}
$$

The replicated dynamics equation of farmers who adopt the strategy of complete implementation is: 


$$
\begin{aligned}
F_{3}(z)= & \frac{d z}{d t}=z\left(U_{f 1}-U_{f}\right) \\
= & z(1-z)\left\{\left[\left(S_{1}-S_{5}\right)-\left(S_{3}-S_{7}\right)\right] x y+\left(S_{3}-S_{7}\right) y\right. \\
& \left.+\left[\left(S_{2}-S_{6}\right)-\left(S_{4}-S_{8}\right)\right] x(1-y)+\left(S_{4}-S_{8}\right)(1-y)\right\}
\end{aligned}
$$

Finally, in the tripartite evolutionary game model of EPC for PSA, the replicated dynamic system consists of (28), (32), and (36).

\section{Evolutionary Stable Strategy}

From the basic theory of EGT, we can know that the probabilities of the three stakeholders who choose the complete implementation strategy vary with time [41]. Eventually, a stable state is reached through the interaction between the three stakeholders. The strategy in this stable state can be referred to as the evolutionary stable strategy (ESS).

When all the dynamic equations equal 0 , as (37) which is, the probabilities of CG, LG, and farmers would no longer evolve. The point at which this condition is met is the equilibrium point. The point corresponding to ESS is included in the equilibrium point. Therefore, the solution of (37) should be found.

$$
\left\{\begin{aligned}
F_{1}(x)= & x(1-x)\left\{\left[\left(Q_{1}-Q_{3}\right)-\left(Q_{5}-Q_{7}\right)\right] y z+\left(Q_{5}-Q_{7}\right) y\right. \\
& \left.+\left[\left(Q_{2}-Q_{4}\right)-\left(Q_{6}-Q_{8}\right)\right](1-y) z+\left(Q_{6}-Q_{8}\right)(1-y)\right\}=0 \\
F_{2}(y)= & y(1-y)\left\{\left[\left(R_{1}-R_{2}\right)-\left(R_{5}-R_{6}\right)\right] x z+\left(R_{5}-R_{7}\right) x\right. \\
& \left.+\left[\left(R_{3}-R_{4}\right)-\left(R_{7}-R_{8}\right)\right](1-x) z+\left(R_{7}-R_{8}\right)(1-x)\right\}=0 \\
F_{3}(z)= & z(1-z)\left\{\left[\left(S_{1}-S_{5}\right)-\left(S_{3}-S_{7}\right)\right] x y+\left(S_{3}-S_{7}\right) y\right. \\
& \left.+\left[\left(S_{2}-S_{6}\right)-\left(S_{4}-S_{8}\right)\right] x(1-y)+\left(S_{4}-S_{8}\right)(1-y)\right\}=0
\end{aligned}\right.
$$

The ESS point can only appear in a combination of pure strategies [45, 46]. Therefore, the asymptotic stability of the pure strategy point needs to be assessed. Lyapunov's System Stability Theory provides a method of assessment, namely eigenvalues of the matrix[47]. When the matrix eigenvalues are negative, the equilibrium point can be stable. According to assumption 2, the purpose of the EPC policy is that all three parties can completely implement the policy, which is also this paper's goal of improving tBased on the above theory, we only need to get the Jacobian matrix of (37) at point $M=(1,1,1)$, that is:

$$
J_{M}=\left(\begin{array}{ccc}
Q_{3}-Q_{1} & 0 & 0 \\
0 & R_{2}-R_{1} & 0 \\
0 & 0 & S_{5}-S_{1}
\end{array}\right)
$$

The matrix eigenvalues of (38) are $\gamma_{1}=Q_{3}-Q_{1}$, $\gamma_{2}=R_{2}-R_{1}$, and $\gamma_{3}=S_{5}-S_{1}$. Point $\mathrm{M}$ will be asymptotically stable only when the three matrix eigenvalues are all less than 0 .
The constraint relationship can be obtained as (39). Only when the parameters satisfy the constraint relationship, the tripartite evolutionary game model evolve into the ESS that is $x=1, y=1$, and $z=1$. The improved EPC policy can evolve toward the preset goal.

$$
\left\{\begin{array}{l}
B_{1}-C_{1}>0 \\
F_{1}+B_{2}+P-\left(1-\lambda_{2}\right)\left(C_{2}+N\right)>0 \\
F_{2}+\left(1-\lambda_{3}\right) T_{2}-\left(1-\lambda_{3}\right) C_{3}>0
\end{array}\right.
$$

Numerical Simulation for the Impact of Parameters on the Evolutionary Game Model

The EPC policy for PSA has been implemented for 6 years in the GW overexploitation area of the BTH. The cost to farmers of implementing the policy was set to $C_{3}$ $=5$ in accordance with the current EPC policy and field research. The degree of farmers' satisfaction to the EPC policy represents their level of effort in implementing. Based on the contribution of Xie et al. [37], the level of the farmers' effort was set to $\lambda_{3}=0.87$. Under the constraints of (39), all parameter settings are as shown in Table 4.

Substituting all the parameters in Table 3 into Equation (37), equation (40) could be derived as the numerical simulation object.

$$
\left\{\begin{aligned}
F_{1}(x)= & \frac{d x}{d t} \\
= & x(1-x)\left(1-\lambda_{1}\right)\left[(1-y) F_{1}+(z-1)\left(1-\lambda_{3}\right) G+B_{1}-C_{1}\right] \\
= & 0 \\
F_{2}(y)= & \frac{d y}{d t} \\
= & y(1-y)\left\{x\left(1-\lambda_{1}\right)\left[F_{1}+P+\left(1-\lambda_{2}\right) C_{2}\right]+z\left[\left(1-\lambda_{3}\right) B_{2}-\left(1-\lambda_{2}\right) F_{2}\right]\right. \\
& \left.+\lambda_{1}\left(F_{1}+P\right)+\left(1-\lambda_{2}\right)\left[F_{2}-N-\left(2-\lambda_{1}\right) C_{2}\right]+\lambda_{3} B_{2}\right\} \\
= & 0 \\
F_{3}(z)= & \frac{d z}{d t} \\
= & z(1-z)\left\{y\left(1-\lambda_{2}\right)\left[F_{2}+\left(1-\lambda_{3}\right) C_{3}\right]+\left(1-\lambda_{3}\right)\left[T-\left(2-\lambda_{2}\right) C_{3}\right]+\lambda_{2} F_{2}\right\} \\
= & 0
\end{aligned}\right.
$$

Table 4. The values of the relevant parameters.

\begin{tabular}{|c|c|c|c|}
\hline Parameters & Value & Parameters & Value \\
\hline$C_{1}$ & 2 & $G$ & 6 \\
\hline$C_{2}$ & 3 & $N$ & 4 \\
\hline$C_{3}$ & 5 & $P$ & 3 \\
\hline$B_{1}$ & 4 & $T$ & 1 \\
\hline$B_{2}$ & 5 & $\lambda_{3}$ & 0.6 \\
\hline$F_{1}$ & 5 & $\lambda_{3}$ & 0.6 \\
\hline$F_{2}$ & 4 & $\lambda_{3}$ & 0.87 \\
\hline
\end{tabular}




\section{Results and Discussion}

\section{The Impact of Initial Probability}

Under the conditions of parameter settings shown in Table 4, the current study performed numerical simulations of the impact of the initial probabilities of stakeholders on changes in strategies over time.

Fig. 4 shows the impact of changes in $x$ on $\mathrm{CG}$ itself and the impact of changes in $y$ or $z$ on the evolution of CG. Under the fixed $y$ and $z$, the value of $\mathrm{x}$ had a positive relationship with the speed at which CG converged to 1 . Comparing Figs. 4a) and d), or Figs 4b) and c), under a constant $z$, the value of $y$ was positively related to the time $t$ required for $x$ to reach the stable state. This result indicated that the increase in the probability of complete implementation by the LG will slow down the rate of the complete implementation strategy by the CG. Under the situation of the initial probability $y$ selected by LG remaining unchanged, by comparing Figs 4a) and c), or Figs 4b) and $\mathrm{d}$ ), an increase in $z$ accelerated the convergence of $x$, although this effect was not significant. This result can be attributed to non-compliance with the policy by farmers only affecting the CG's remediation cost. In the maximum $\mathrm{y}$ and minimus $\mathrm{x}$ scenario, the early stage of evolution showed a slowing trend, compared to other scenarios. This may be closely related to the implementation degree of the LG, resulting in a maintain of CG at the low level of supervision and policy guidance. However, this phenomenon was transient.

The impact of initial probability on the evolution of LG was shown in Fig. 5. Before convergence, $y$ increased monotonically with increasing $t$, with the value of $y$ positively related with the speed at which LG reached an ideal state. When the value of $x$ was fixed, the increase in $z$ slowed down the convergence rate of $y$. This result is clearly due to the behavior of farmers of fully implementing the policy resulting in a reduction of pressure on the LG to supervise. In contrast, under the condition of a fixed $z$, the increase in the initial probability of CG will accelerate the convergence of $y$ to the ideal state. LG plays the role of the linker in the entire gaming system.

Fig. 6 shows the impact of the initial probability of each stakeholder on the evolution of $z$. By comparing Figs. 6a) and d), or b) and c), it is clear that $x$ had almost no impact on the evolution of $z$. The initial probability of LG influenced the strategies adopted by farmers. The larger the value of $y$, the faster $z$ approached 1. Regardless of changes to $y, z$ eventually converged to 1 .

\section{The Impact of Variation in Parameters on the Results}

An analysis of the impact of different parameters on the model was conducted by varying individual parameters while keeping the remainder unchanged, and then assessing the model results. At the same time, the impact of parameter variation on the evolution of a certain stakeholder was assessed by setting the initial probabilities of the remaining two stakeholders to 0.6. Based on the above, the impacts of cost, penalty, the level of effort, and other parameters on the model were assessed.

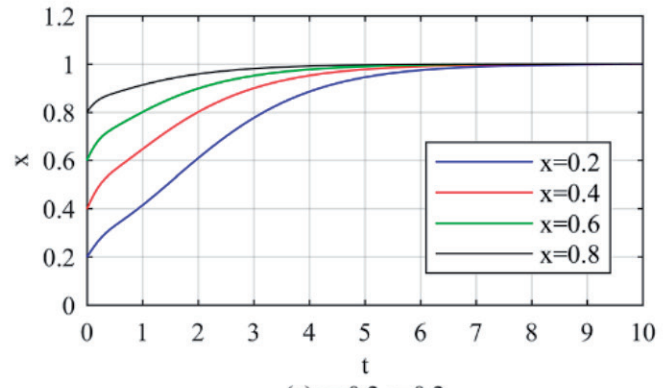

(a) $\mathrm{y}=0.2, \mathrm{z}=0.2$

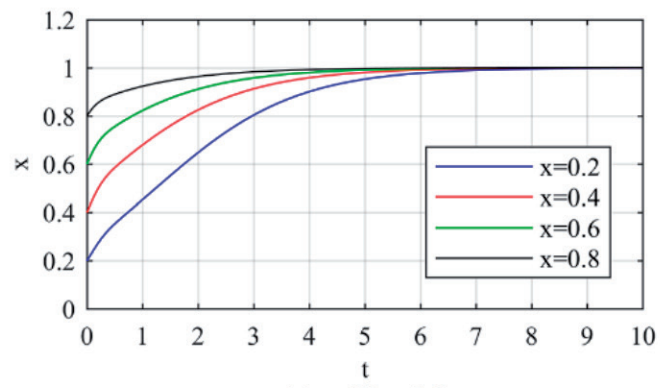

(c) $\mathrm{y}=0.2, \mathrm{z}=0.8$

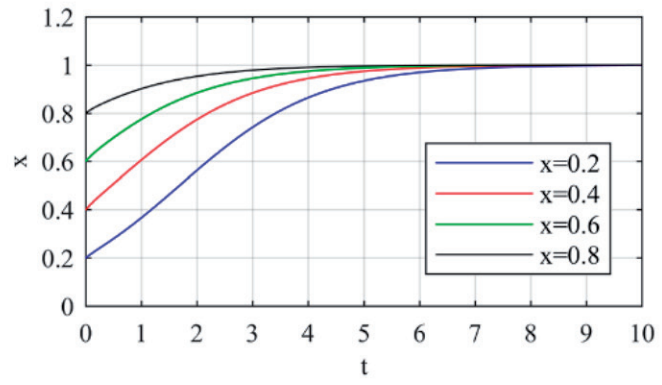

(b) $\mathrm{y}=0.8, \mathrm{z}=0.8$

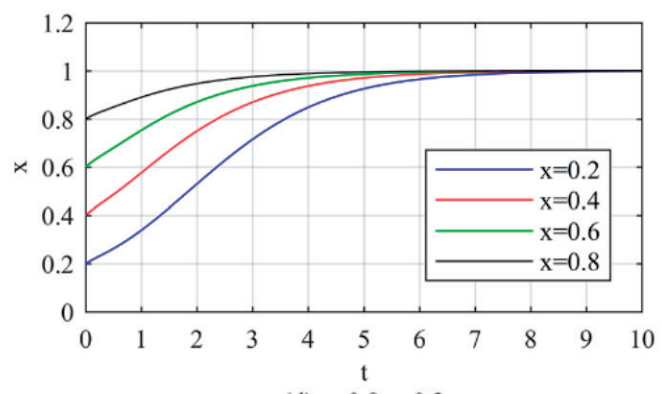

(d) $\mathrm{y}=0.8, \mathrm{z}=0.2$

Fig. 4. The impact of initial probability on the evolution of CG. 


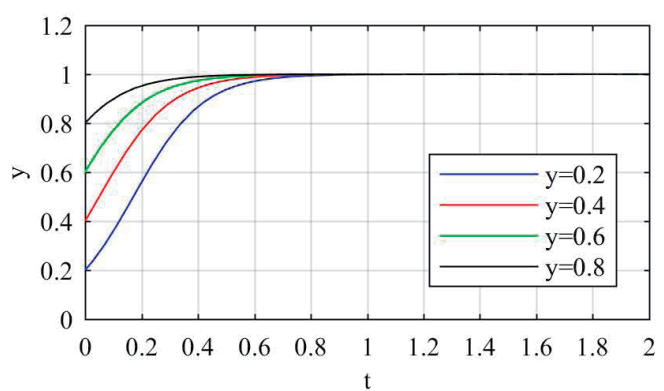

(a) $\mathrm{x}=0.2, \mathrm{z}=0.2$

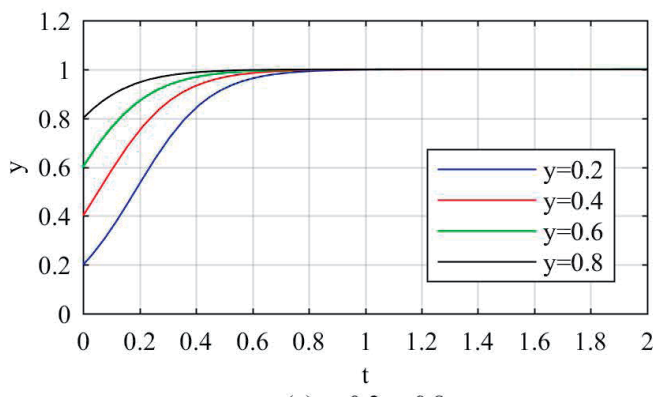

(c) $\mathrm{x}=0.2, \mathrm{z}=0.8$

Fig. 5. The impact of initial probability on the evolution of LG.

\section{Cost of Implementation}

Equations (28), (32), and (36) show that the cost of each stakeholder will only affect its own evolution. Since stakeholders often seek to maximize their own payoffs, they will attempt to reduce their costs. Assuming that the cost is reduced by half, then the evolution paths of the CG, LG, and farmers will correspond to the dotted lines in Fig. 7a), b), and c), respectively. Clearly, cost reduction can accelerate the evolution to the stable state.

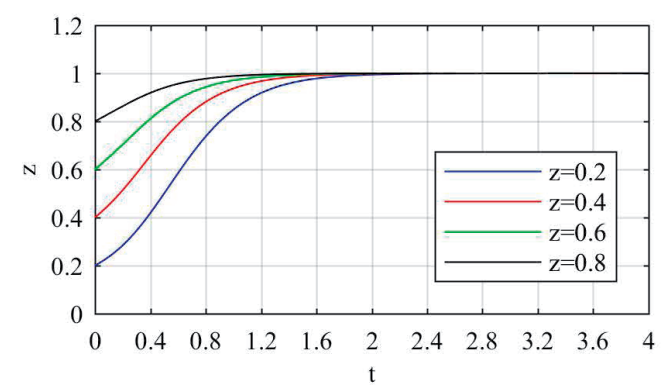

(a) $\mathrm{x}=0.2, \mathrm{y}=0.2$

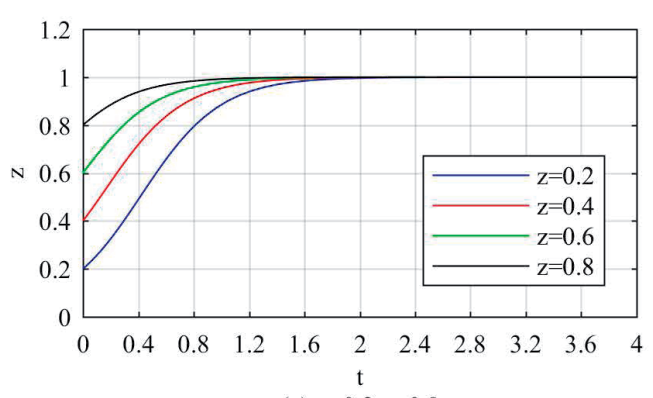

(c) $\mathrm{x}=0.2, \mathrm{y}=0.8$

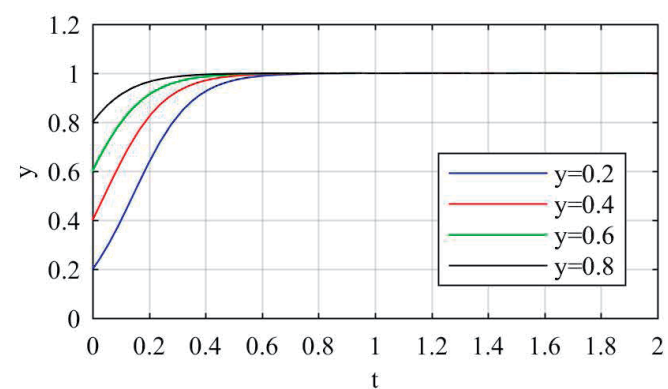

(b) $x=0.8, z=0.8$

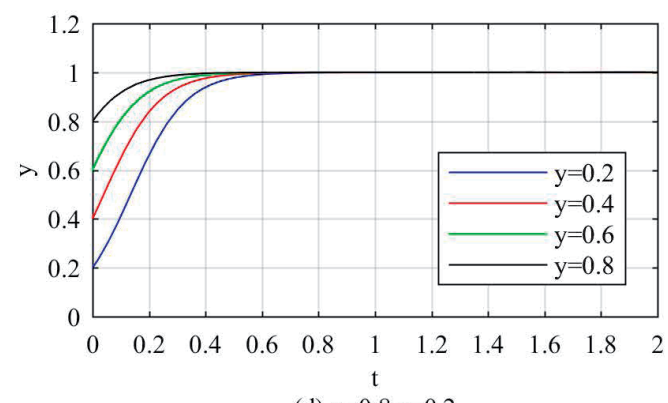

(d) $\mathrm{x}=0.8, \mathrm{z}=0.2$

This acceleration was more prominent in the evolution process of CG. Thus, in the implementation process, the costs of policy implementation should be reduced, which is especially important for governments.

\section{Penalty of Partial Implementation}

The penalty is an economic price paid by the supervised entity for violations of an agreed policy. However, the current EPC policy is missing a penalty

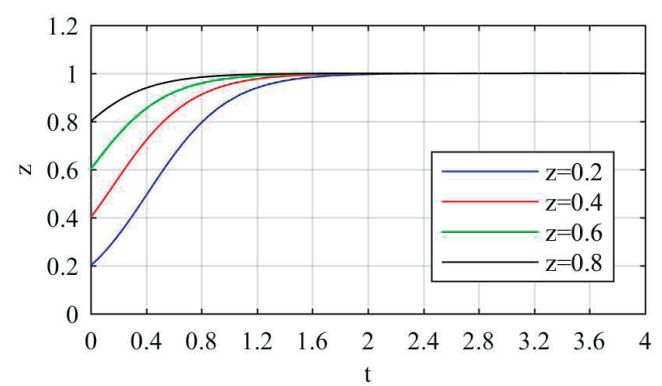

(b) $\mathrm{x}=0.8, \mathrm{y}=0.8$

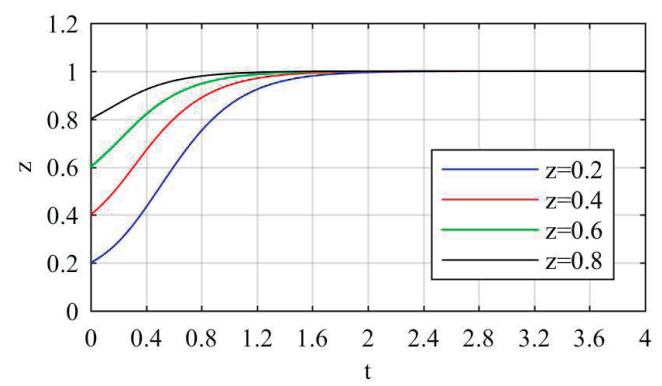

(d) $\mathrm{x}=0.8, \mathrm{y}=0.2$

Fig. 6. The impact of initial probability on the evolution of farmers. 
system. Thus, the present study examined the impact of penalties between the supervisor and the supervised on the evolution of strategies.

Fig. 8 explores a case under which the $\mathrm{CG}$ has increased penalty $F_{1}$ for $\mathrm{LG}$ due to the failure of $\mathrm{LG}$ to fully perform its duties, holding all other parameters unchanged. When $F_{1}$ was increased from 5 to 10 , the time required for $\mathrm{LG}$ to converge to 1 was significantly reduced. In contrast, $\mathrm{CG}$ was not sensitive to the increase in penalty.

Fig. 9 shows a similar situation when exploring a situation in which LG imposed the penalty $F_{2}$ from 4.0 to 8.0 on farmers. As shown in Fig. 9a), although the penalty did not significantly accelerate the convergence of $\mathrm{LG}$, an increase in $F_{2}$ did increase the rate at which the farmers reached a stable state.

\section{Level of Effort}

The level of effort represents the willingness and technical ability of stakeholders to participate in EPC for PSA under the current conditions. Keeping other

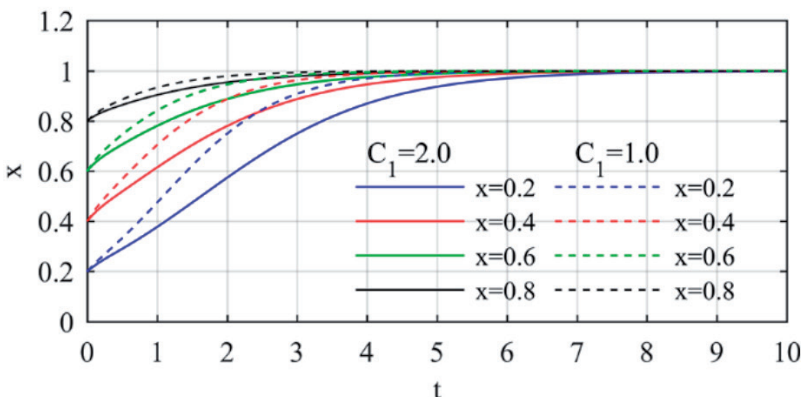

(a) $\mathrm{y}=0.6, \mathrm{z}=0.6$

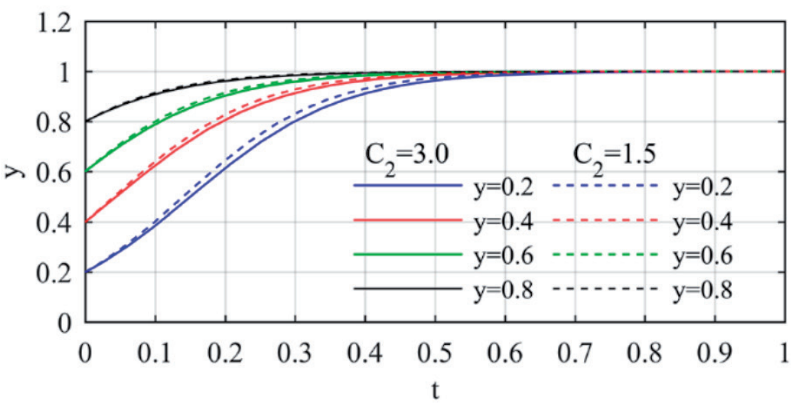

(b) $\mathrm{x}=0.6, \mathrm{z}=0.6$

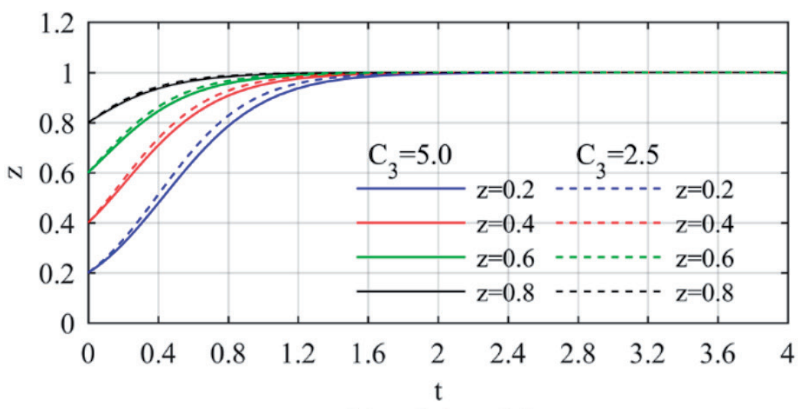

(c) $\mathrm{x}=0.6, \mathrm{y}=0.6$

Fig. 7. The impact of cost on the evolution of the model. parameters unchanged, the level of effort was reduced by half of the current level, with the results shown in Figs 10, 11, and 12 for the CG, LG, and farmers, respectively.

When the effort level of CG decreases to $\lambda_{1}=0.3$, the evolution of farmers has not been affected in any way from Fig. 10c). For $\mathrm{LG}$, the behavior of $\mathrm{CG}$ to

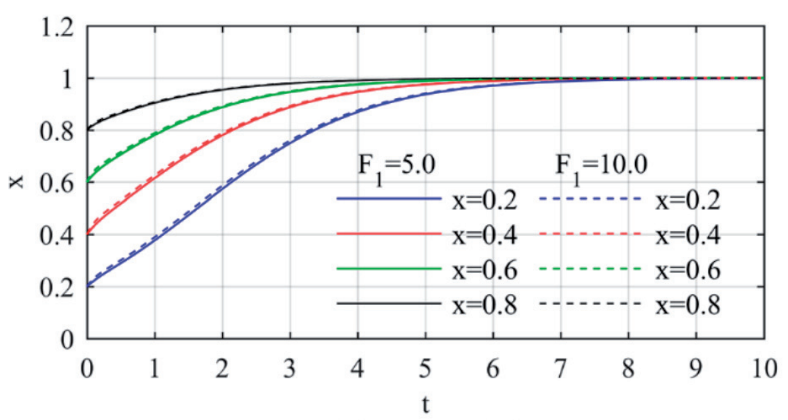

(a) $y=0.6, z=0.6$

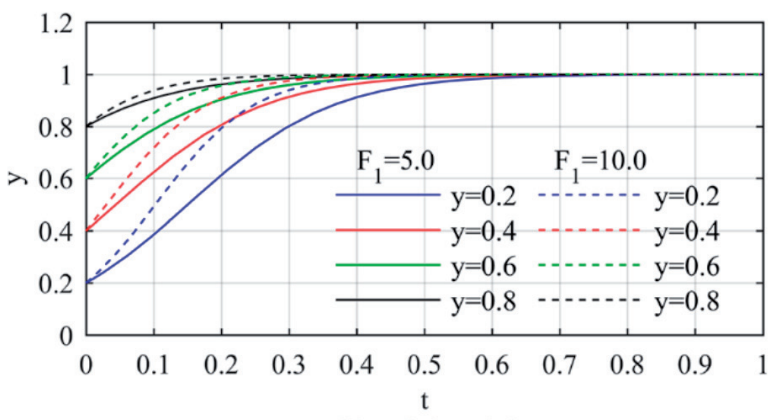

(b) $\mathrm{x}=0.6, \mathrm{z}=0.6$

Fig. 8. The impact of $F_{1}$ on the evolution of CG and LG.

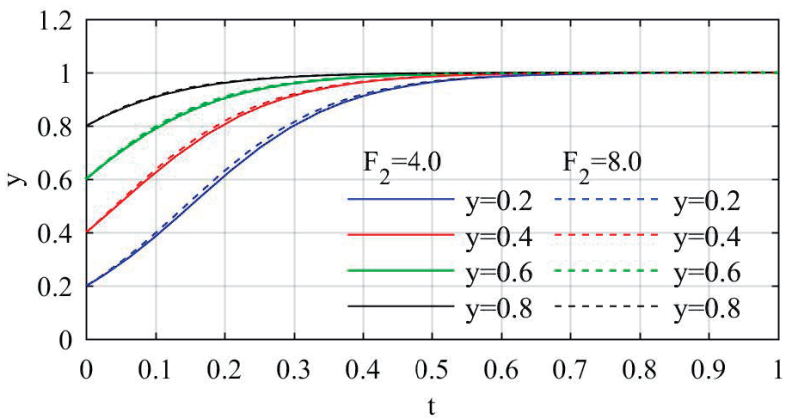

(a) $\mathrm{x}=0.6, \mathrm{z}=0.6$

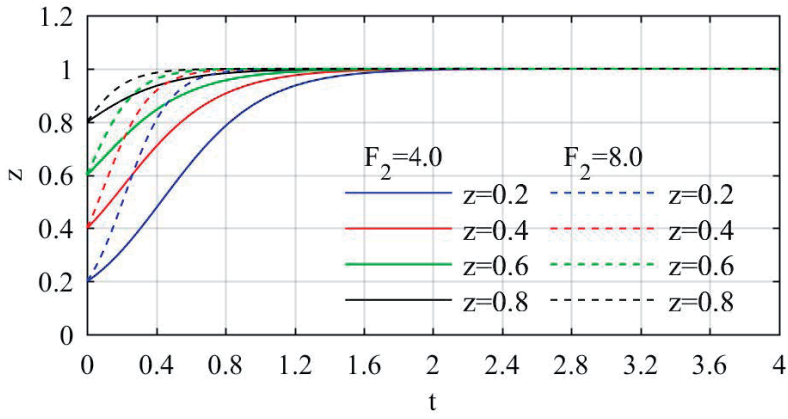

(b) $x=0.6, y=0.6$

Fig. 9. The impact of $F_{2}$ on the evolution of LG and farmers. 


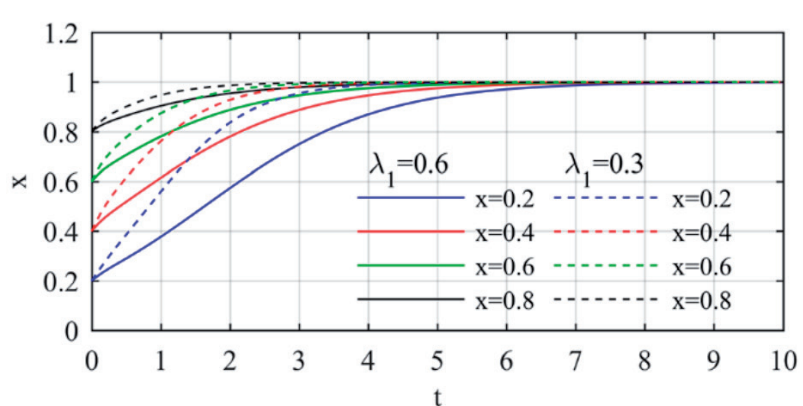

(a) $\mathrm{y}=0.6, \mathrm{z}=0.6$

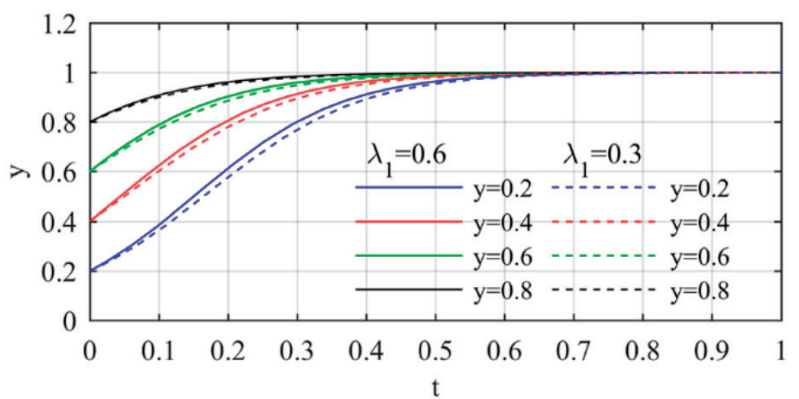

(b) $\mathrm{x}=0.6, \mathrm{z}=0.6$

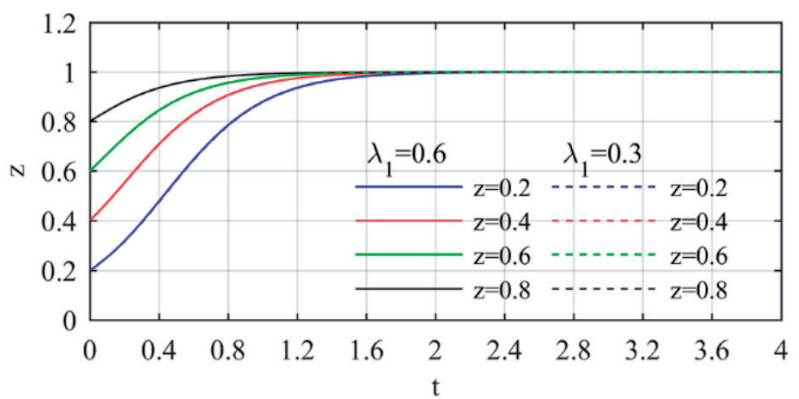

(c) $\mathrm{x}=0.6, \mathrm{y}=0.6$

Fig. 10. The impact of $\lambda_{1}$ on the evolution of entire system.

lower the level of policy guidance and supervision will slow down the process of LG's convergence to 1 . This is due to the lack of policy guidance from $C G$, which has caused an increase in cost to be greater than the decrease in penalty and political loss. For CG itself, shown in Fig. 10a), the lower the effort level, the faster CG reaches the stable state. CG is much more sensitive to change in $\lambda_{1}$ than LG. Facing the fact that China is a unitary government-type developing country, the level of LG governance still needs to be improved. The CG is prone to encounter the dilemma of conflicts between its own interests and collective interests, which always leads to the sacrifice of CG's interests. The increase in the CG's level of effort will prompt LG to reach the stable state more quickly. This means that the CG will invest more in supervision and policy guidance.

Fig. 11 shows the impact of the change of $\lambda_{2}$ on the entire evolution of strategies. The level of effort by the LG had almost no impact on the evolution of CG. Obviously, the information asymmetry between CG and LG has caused the CG's inability to fully perceive the level of effort by LG. A reduction in the level of effort by the LG in providing agricultural technical

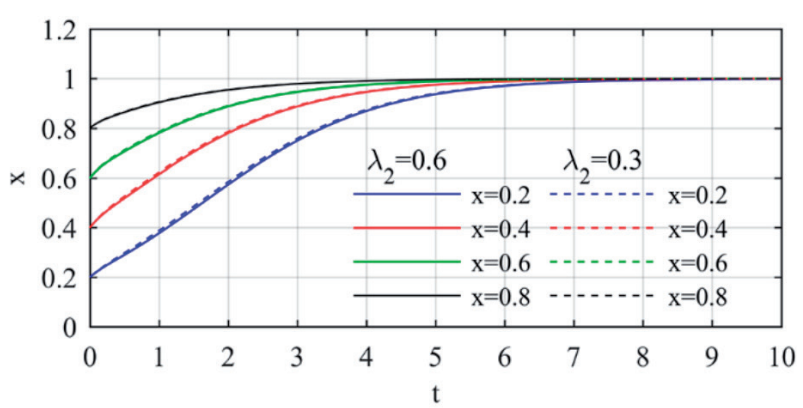

(a) $y=0.6, z=0.6$

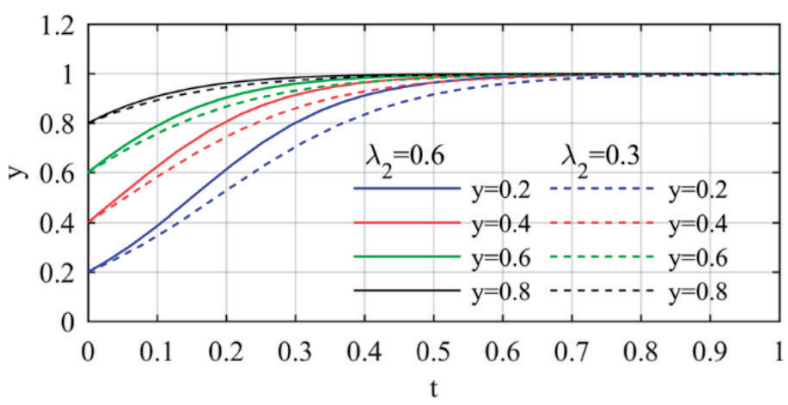

(b) $\mathrm{x}=0.6, \mathrm{z}=0.6$

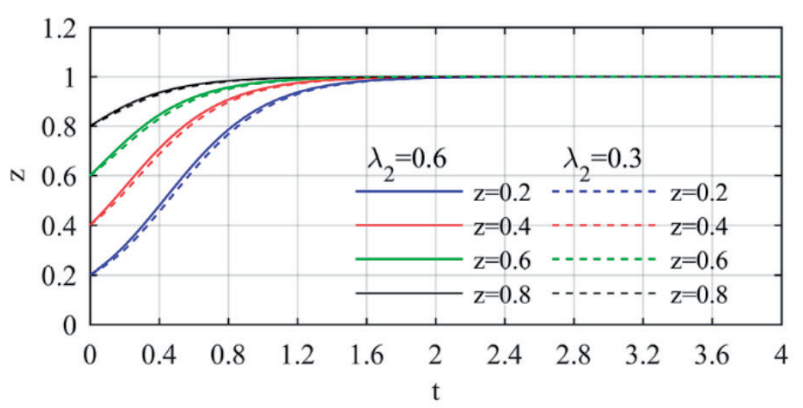

(c) $x=0.6, y=0.6$

Fig. 11. The impact of $\lambda_{2}$ on the evolution of entire system.

support and supervision to farmers had no effect on the direction of convergence by LG. But it will extend the time of LG's convergence. As $\lambda_{2}$ decreases from 0.6 to 0.3 , the evolution of farmers to a stable state was slightly hindered. This fully demonstrates the bridging role of LG in the implementation of top-down policy.

As shown in Fig. 12, the reduction of the level of effort by farmers reduced the speed at which the entire system tended to stabilize. The current study explored a situation under which the level of effort by farmers $\lambda_{3}$ was reduced by half from 0.87 under the current situation to 0.43. By comparing Figs $12(\mathrm{a}-\mathrm{c})$, it is clear that the reduction of $\lambda_{3}$ had the greatest impact on mitigating convergence by farmers. From a governmental perspective, despite the LG being responsible for the direct management of farmers, the CG is more affected compared to the LG. This result can be attributed to CG having to pay the remedial cost $G$ resulting from the partial implementation of the policy by farmers. It is undeniable that improving the level of farmers' effort to implement policy is the key to improving the effectiveness of policy. This promotion works in a down-top manner. Thus, the formulation of 


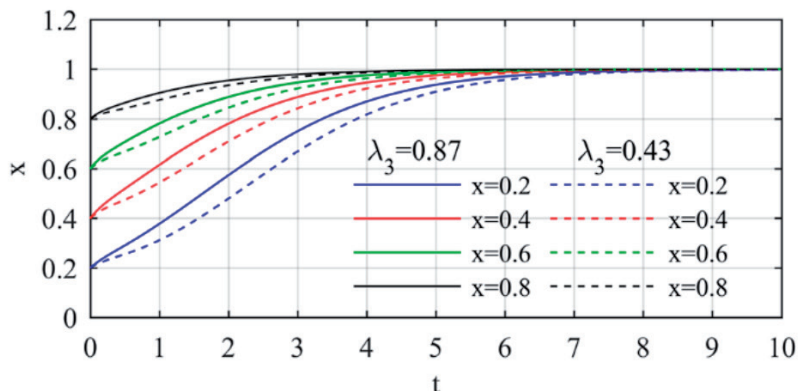

(a) $\mathrm{y}=0.6, \mathrm{z}=0.6$

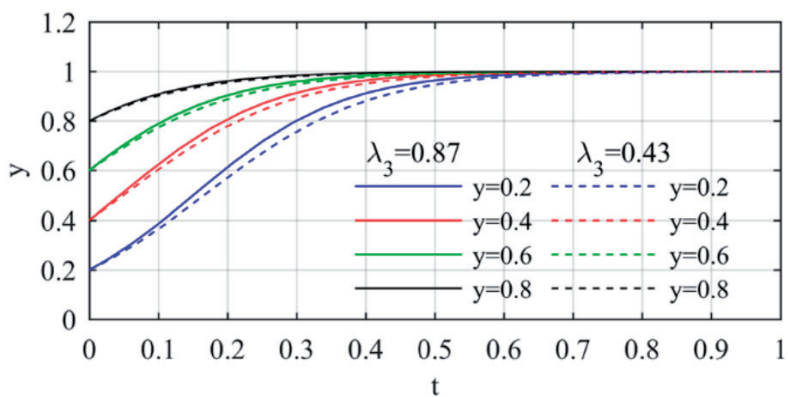

(b) $\mathrm{x}=0.6, \mathrm{z}=0.6$

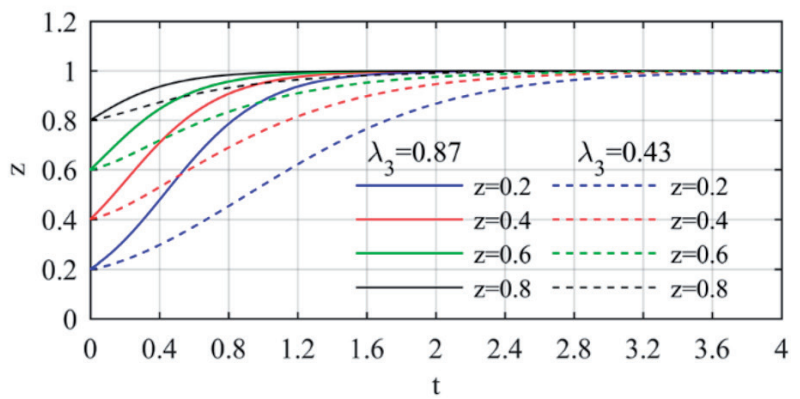

(c) $x=0.6, y=0.6$

Fig. 12. The impact of $\lambda_{3}$ on the evolution of entire system.

EPC policy should follow the principle of stimulating farmers' willingness to participate autonomously to the greatest extent.

\section{Income of Labor Transfer}

Fig. 13 shows the impact of the increase in labor transfer income $T$ on the evolutionary path of farmers

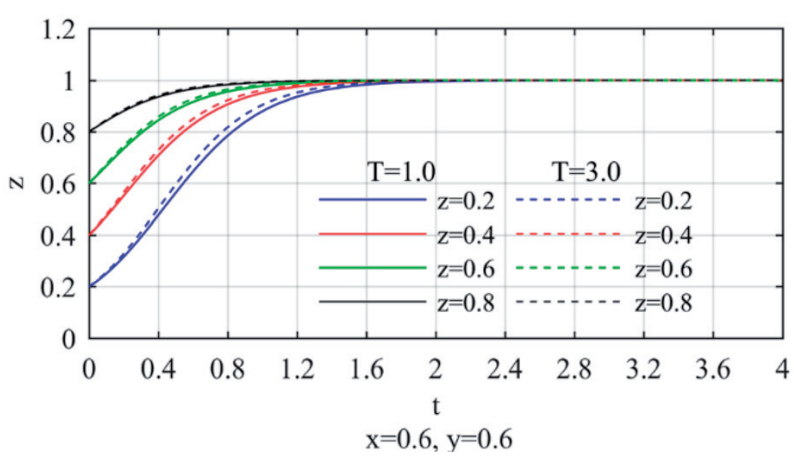

Fig. 13. The impact of $T$ on the evolution of farmers. while keeping all other parameters unchanged. Equation (40) indicates that the change of $T$ has no impact on the evolutionary paths of CG and LG. The increase in $T$ will encourage a more rapid adoption of the complete implementation strategy by farmers.

The results of the actual survey showed that the family income structure of farmers can influence the strategies they adopt [48]. Specifically, farmers with a higher proportion of non-agricultural income are more inclined to fallow completely. This finding can explain the phenomenon shown in Fig. 13. In other words, an increase in $T$ could improve farmers' satisfaction with the EPC policy, which means that farmers' level of effort $\left(\lambda_{3}\right)$ would increase. As a corresponding result, the time for the entire system to reach the state of convergence would be shortened.

\section{Conclusions}

EPC policy for PSA plays a vital role in promoting the control of $\mathrm{GW}$ overexploitation within the BTH region. The original intention of the EPC policy was to protect the environment while considering equitable compensation for farmers. However, this policy underperformed during implementation. The present study aimed to improve the EPC policy in formulation and implementation from a sustainability perspective. A tripartite evolutionary game model involving CG, LG, and farmers was constructed. By analyzing the ESS of this model, the constraints that should be met to achieve the expected goals of EPC policy were established. Finally, the impact of initial probability and four types of parameters on the evolution of strategies was analyzed through numerical simulation. The conclusions of the current study include:

(1) The current study improved the EPC policy in two ways for the purpose of enhancing the sustainability of this policy. In terms of policy design, EPC policy should contain provisions that can be used to impose an economic penalty for violations of the policy. In terms of stakeholders' payoffs, the long-term impacts of partial implementation must be taken into consideration, including remedial cost borne by CG, the political loss of CG or LG, additional costs of LG or farmers, economic penalties of LG or farmers, and the level of effort by each stakeholder.

(2) The ideal purpose of formulating the EPC policy was to achieve complete implementation by CG, LG, and farmers, which means that the ESS of the established tripartite evolutionary game model should be $(x, y, z)=(1,1,1)$. Under this premise, the three constraints that the parameters must satisfy at the same time are as follows: (i) for CG, political losses should be greater than the cost of supervision and guidance; (ii) for LG, the sum of economic penalty, political loss, and political accountability loss should be greater than the benefits obtained by adopting partial implementation strategies, including cost savings and additional benefit; 
(iii) as for farmers, the total value, including economic penalty and the reduction of labor transfer income, must be greater than the saved cost.

(3) The initial probabilities of CG, LG, and farmers fully implementing the policy can affect the evolutionary game process, and meanwhile, the evolution direction remains unchanged. The greater the initial probability of the CG fully implementing the EPC policy, the faster LG will reach the stable state. The greater the initial probability of the LG fully implementing the policy, the more time required for $\mathrm{CG}$ to reach the stable state. The same phenomenon occurs between LG and farmers. Thus, it is particularly important to obtain further information on policy acceptance before policy implementation.

(4) Although reducing the cost of implementing EPC policy for the three stakeholders is an effective method of accelerating their evolution, this does not have an impact on other stakeholders. The implementation of a penalty system clearly promotes the evolution of the supervised to ESS. Improving the level of effort by farmers is key to accelerating the evolution of the entire system. An increase in farmer income during the fallow period can be an effective way to promote farmers to adopt the strategy of complete implementation.

\section{Acknowledgment}

This work was supported by National Natural Science Foundation of China (Grant No. 51979221), by Natural Science Basic Research Program of Shaanxi (Program No. 2021JLM-45), and by Research Fund of the State Key Laboratory of Eco-hydraulics in Northwest Arid Region, Xi'an University of Technology (Grant No. 2019KJCXTD-5).

\section{Conflict of Interest}

The authors declare no conflict of interest.

\section{References}

1. WU Z.Z., JIANG M.Y., CAI Y.Z., WANG H., LI S.H. What Hinders the Development of Green Building? An Investigation of China. International Journal of Environmental Research and Public Health, 16 (17), 1, 2019.

2. SHENG J.C., ZHOU W.H., ZHU B.Z. The coordination of stakeholder interests in environmental regulation: Lessons from China's environmental regulation policies from the perspective of the evolutionary game theory. Journal of Cleaner Production, 249, 13, 2020.

3. LO C.W.-H., FRYXELL G.E., WONG W.W.-H. Effective Regulations with Little Effect? The Antecedents of the Perceptions of Environmental Officials on Enforcement Effectiveness in China. Environmental Management, 38 (3), 388, 2006.
4. YANG Z.J., KONG X.C., SUN J., ZHANG Y.L. Switching to Green Lifestyles: Behavior Change of Ant Forest Users. International Journal of Environmental Research and Public Health, 15 (9), 1, 2018.

5. LI B.L., RODELL M., SHEFFIELD J., WOOD E., SUTANUDJAJA E. Long-term, non-anthropogenic groundwater storage changes simulated by three globalscale hydrological models. Scientific Reports, 9, 1, 2019.

6. LONG D., YANG W.T., SCANLON B.R., et al. South-toNorth Water Diversion stabilizing Beijing's groundwater levels. Nature Communications, 11 (1), 10, 2020.

7. GUO M.J., JIANG Z.Y., BU Y., CHENG J.H. Supporting Sustainable Development of Water Resources: A Social Welfare Maximization Game Model. International Journal of Environmental Research and Public Health, 16 (16), 15, 2019.

8. WANG Z.Q., WU A.G., CIACCHI L.C., WEI G. Recent Advances in Nanoporous Membranes for Water Purification. Nanomaterials, 8 (2), 19, 2018.

9. YUE W.C., CAI Y.P., XU L.Y., YANG Z.F., YIN X.A., SU M.R. Industrial water resources management based on violation risk analysis of the total allowable target on wastewater discharge. Scientific Reports, 7, 11, 2017.

10. LEAS E.C., DARE A., AL-DELAIMY W.K. Is gray water the key to unlocking water for resource-poor areas of the Middle East, North Africa, and other arid regions of the world? Ambio, 43 (6), 707, 2014.

11. SMITH R., KNIGHT R., FENDORF S. Overpumping leads to California groundwater arsenic threat. Nature Communications, 9, 6, 2018.

12. RODELL M., FAMIGLIETTI J.S., WIESE D.N., et al. Emerging trends in global freshwater availability. Nature, 557 (7707), 650, 2018

13. DONG Y., JIANG C.S., SURI M.R., PEE D., MENG L.K., GOLDSTEIN R.E.R. Groundwater level changes with a focus on agricultural areas in the Mid-Atlantic region of the United States, 2002-2016. Environmental Research, 171, 193, 2019.

14. MASSOUD E.C., PURDY A.J., MIRO M.E., FAMIGLIETTI J.S. Projecting groundwater storage changes in California's Central Valley. Scientific Reports, 8, 9, 2018.

15. BASSI N. Assessing potential of water rights and energy pricing in making groundwater use for irrigation sustainable in India. Water Policy, 16 (3), 442, 2013.

16. JOODAKI G., WAHR J., SWENSON S. Estimating the human contribution to groundwater depletion in the Middle East, from GRACE data, land surface models, and well observations. Water Resources Research, 50 (3), 2679, 2014.

17. LIU R.L., ZOU R., LI J.C., ZHANG C.H., ZHAO B., ZHANG Y.K. Vertical Displacements Driven by Groundwater Storage Changes in the North China Plain Detected by GPS Observations. Remote Sensing, 10 (2), 13, 2018.

18. PAN Y., YU Z., HOLST J., DOLUSCHITZ R. Integrated assessment of cropping patterns under different policy scenarios in Quzhou County, North China Plain. LAND USE POLICY, 40, 131, 2014.

19. JIANG W.L. Study on Water Resource Safety Strategy for China in the $21^{\text {th }}$ Century. Advances in Water Science, 12 (01), 66, 2001.

20. WANG X.Y., SUN L. Discussion on Geological Hazards Caused by Exploitation of Deep Groundwater in North China. Engineering Geology for Society And Territory, 
Vol 5: Urban Geology, Sustainable Planning And Landscape Exploitation; 667-673, Italy, 2015.

21. CHEN J., BROUSSARD W.P., BORROK D.M., SPEYRER F.B. A GIS-Based Framework to Identify Opportunities to Use Surface Water to Offset Groundwater Withdrawals. Water Resources Management, 33 (9), 3227, 2019.

22. HAROU J.J., LUND J.R. Ending groundwater overdraft in hydrologic-economic systems. Hydrogeology Journal, 16 (6), 1039, 2008.

23. FAMIGLIETTI J.S. The global groundwater crisis. Nature Clim ate Change, 4 (11), 945, 2014.

24. CHEN M., TOMÁS R., LI Z., et al. Imaging Land Subsidence Induced by Groundwater Extraction in Beijing (China) Using Satellite Radar Interferometry. Remote Sensing, 8 (6), 468, 2016.

25. SHEN D.J. Groundwater management in China. Water Policy, 17 (1), 61, 2014.

26. YU L.L., LING M.H., CHEN F., DING Y.Y., LV C.M. Practices of groundwater over-exploitation control in Hebei Province. Water Policy, 22 (4), 591, 2020.

27. Tianjin Water Resources Bulletin. Available online: http:// swj.tj.gov.cn/gztb_17212/(accessed on 15 November 2020).

28. Beijing Water Resources Bulletin. Available online: http:// swj.beijing.gov.cn/zwgk/szygb/ (accessed on 15 July 2020).

29. Hebei Water Resources Bulletin. Available online: http:// slt.hebei.gov.cn/ (accessed on 15 June 2020).

30. BAO X., LI Z., XIE F. Environmental influences on light response parameters of net carbon exchange in two rotation croplands on the North China Plain. Scientific Reports, 9 (1), 1, 2019.

31. LIU X., REN Y., GAO C., YAN Z., LI Q. Compensation effect of winter wheat grain yield reduction under straw mulching in wide-precision planting in the North China Plain. Scientific Reports, 7 (1), 213, 2017.

32. LUO J., SHEN Y., QI Y., ZHANG Y., XIAO D. Evaluating water conservation effects due to cropping system optimization on the Beijing-Tianjin-Hebei plain, China. Agricultural Systems, 159, 32, 2018.

33. DENG H.B., GUAN B.Z., WANG J.X., ZUO A., WANG Z.A.L., SUN T.H. Seasonal Land Fallowing Policy in Response to Groundwater Overdraft in the North China Plain. Water Alternatives-an Interdisciplinary Journal on Water Politics and Development, 14 (2), 371, 2021.

34. YU H., XIE W., YANG L., DU A., ALMEIDA C., WANG Y. From payments for ecosystem services to ecocompensation: Conceptual change or paradigm shift? Science of the Total Environment, 700, 134627, 2020.

35. YANG W.J., GONG Q.W., ZHANG X.Y. Surplus or deficit? Quantifying the total ecological compensation of Beijing-Tianjin-Hebei Region. Journal of Geographical Sciences, 30 (4), 621, 2020.

36. LIU M.C., YANG L., MIN Q.W., BAI Y.Y. Ecocompensation standards for agricultural water conservation: A case study of the paddy land-to-dry land program in China. Agricultural Water Management, 204, 192, 2018.

37. CHU X., ZHAN J.Y., WANG C., HAMEEDA S., WANG X.R. Households' Willingness to Accept Improved Ecosystem Services and Influencing Factors: Application of Contingent Valuation Method in Bashang Plateau, Hebei Province, China. Journal of Environmental Management, 255, 10, 2020.

38. XIE H.L., CHENG L.J., LV T.G. Factors Influencing Farmer Willingness to Fallow Winter Wheat and Ecological Compensation Standards in a Groundwater Funnel Area in Hengshui, Hebei Province, China. Sustainability, 9 (5), 18, 2017.

39. LIU H.B., DONG P.W., QIAO K., ZENG Y.C., FU Z.T. Applying Regulations in the Embryonic Energy CivilMilitary Integration Industry to Achieve Sustainable Development: A Tripartite Evolutionary Game Study. Ieee Access, 8, 174032, 2020.

40. LU S.B., WU X.H., SUN H.P., LI W., TANG Y. The multiuser evolutionary game simulation in water quality-based water source system. Environmental Geochemistry and Health, 42 (3), 863, 2020.

41. GAO X., SHEN J.Q., HE W.J., et al. An evolutionary game analysis of governments' decision-making behaviors and factors influencing watershed ecological compensation in China. Journal of Environmental Management, 251, 19, 2019.

42. SHENG J.C., WEBBER M. Incentive-compatible payments for watershed services along the Eastern Route of China's South-North Water Transfer Project. Ecosystem Services, 25, 213, 2017.

43. LI X., YANG X., WEI Q., ZHANG B. Authoritarian environmentalism and environmental policy implementation in China. Resources, Conservation and Recycling, 145, 86, 2019.

44. CUI H.R., ZHAO T., TAO P.J. Evolutionary Game Study on the Development of Green Agriculture in China Based on Ambidexterity Theory Perspective. Polish Journal of Environmental Studies, 28 (3), 1093, 2019.

45. FRIEDMAN D. On economic applications of evolutionary game theory. Journal of Evolutionary Economics, 8, 15, 1998.

46. MA Y.H., WAN Z.Y., JIN C.H. Evolutionary Game Analysis of Green Production Supervision Considering Limited Resources of the Enterprise. Polish Journal of Environmental Studies, 30 (2), 1715, 2021.

47. LYAPUNOV A.M. The general problem of the stability of motion. International Journal of Control, 55 (3), 531, 1992.

48. XIE H., JIN S. Evolutionary Game Analysis of Fallow Farmland Behaviors of Different Types of Farmers and Local Governments. LAND USE POLICY, 88, 1, 2019. 